\title{
Analysis of extreme wave events on the southern coast of Brazil
}

\author{
P. V. Guimarães ${ }^{1,3}$, L. Farina ${ }^{2,3}$, and E. E. Toldo Jr. ${ }^{1}$ \\ ${ }^{1}$ Instituto de Geociências, Universidade Federal do Rio Grande do Sul, Campus do Vale Av. Bento Gonçalves 9500, \\ Porto Alegre, RS, Brasil \\ ${ }^{2}$ Instituto de Matemática, Universidade Federal do Rio Grande do Sul, Campus do Vale Av. Bento Gonçalves 9500, \\ Porto Alegre, RS, Brasil \\ ${ }^{3}$ BCAM, Basque Center for Applied Mathematics, Alameda de Mazarredo, 14, 48009, Bilbao, Basque Country, Spain
}

Correspondence to: P. V. Guimarães (pvguima@gmail.com)

Received: 14 May 2014 - Published in Nat. Hazards Earth Syst. Sci. Discuss.: 17 June 2014

Revised: 9 September 2014 - Accepted: 25 October 2014 - Published: 3 December 2014

\begin{abstract}
Using the wave model SWAN (simulating waves nearshore), high waves on the southwestern Atlantic generated by extra-tropical cyclones are simulated from 2000 to 2010, and their impact on the Rio Grande do Sul (RS) coast is studied. The modeled waves are compared with buoy data and good agreement is found. The six extreme events in the period that presented significant wave heights above $5 \mathrm{~m}$, on a particular point of interest, are investigated in detail. It is found that the cyclogenetic pattern between the latitudes 31.5 and $34^{\circ} \mathrm{S}$ is the most favorable for developing high waves. Hovmöller diagrams for deep water show that the region between the south of Rio Grande do Sul up to a latitude of $31.5^{\circ} \mathrm{S}$ is the most energetic during a cyclone's passage, although the event of May 2008 indicates that the location of this region can vary, depending on the cyclone's displacement. On the other hand, the Hovmöller diagrams for shallow water show that the different shoreface morphologies were responsible for focusing or dissipating the waves' energy; the regions found are in agreement with the observations of erosion and progradation regions. It can be concluded that some of the urban areas of the beaches of Hermenegildo, Cidreira, Pinhal, Tramandaí, Imbé and Torres have been more exposed during the extreme wave events on the Rio Grande do Sul coast, and are more vulnerable to this natural hazard.
\end{abstract}

\section{Introduction}

Storms are one of the most important natural hazards to nearshore urban areas, resulting in property destruction and lives lost (Almeida et al., 2012). The strong winds over the ocean favor the air-sea momentum transfer that is responsible for the ocean disturbances, which may lead to high sea waves affecting navigation, and petroleum platforms, causing severe shore erosion, flooding and other damages on the coast. Thus, the understanding of the dynamics and climate of waves and winds is of major relevance for preventing and mitigating the natural threats.

The mid-latitude cyclogenesis with low-pressure centers in the deep ocean and along the coast increases the intensity of Mid-Atlantic storms, causing extreme storm surges and storm waves (Calliari et al., 1998b). Storm surges are also the major geological risk in low coastal areas. They are often associated with significant losses of life and property. Additionally, sea level elevations at the shore can be further amplified by the presence of shelf waves and by the piling up of water due to wave breaking processes in the surf zone (wave setup).

So, the impact of storms on sandy coasts are induced by different morphodynamic responses, which significantly modify the coastal landscape over short time periods. The magnitude of these processes, such as beach and dune erosion, and the resulting changes are controlled by the combination of storm characteristics and coastal geomorphology (e.g., Morton, 2002).

A number of articles examine coastal storms by means of variables, such as wave energy (Sénéchal et al., 2009), wave height (Wright and Short, 1984), maximum water level reached by waves (Sallenger, 2000), surge level (Wright et al., 1985) and other inundation parameters (Mendoza and Jimenez, 2006, 2009). 


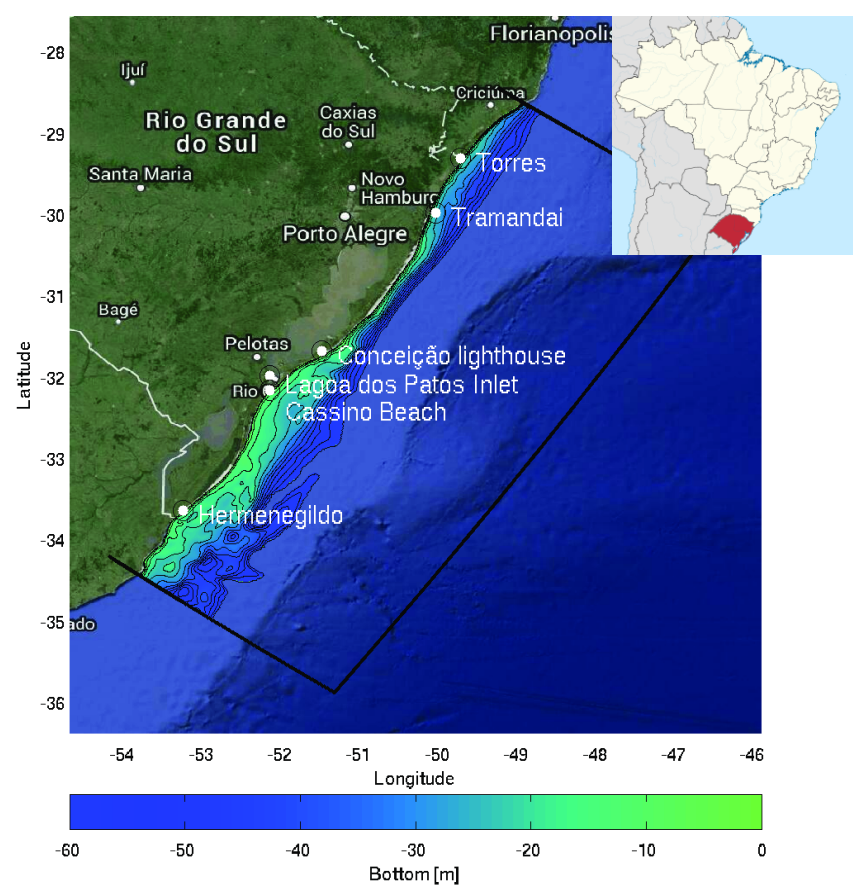

Figure 1. Study field representation. Solid lines represent the the grid boundaries. Inside, on the color scale, the grid bathymetry is between 0 and $-60 \mathrm{~m}$. The points indicate reference beaches at Rio Grande do Sul. Tramandaí beach is where the buoy was placed for the comparison analysis. The maps are plotted over a Google Maps image.

Data on waves and tidal level in the South Atlantic is very scarce. Thus, numerical simulations of extreme events have been the first approach to study the potential damage of storm events. On the Rio Grande do Sul (RS) coast in Brazil, storm events have been investigated by Calliari et al. (1998b), Parise et al. (2009) and Machado et al. (2010).

The state of Rio Grande do Sul is characterized by an extensive coastline with uniform NE-SW orientation and a light sinuosity along its extension of $615 \mathrm{~km}$ (Fig. 1), including on Cassino Beach, one of the longest sandy beaches in the world (Dillenburg et al., 2004). All this extension consists of unconsolidated deposits from quaternary rivers that do not receive contributions from modern sands. The continental shelf is part of a broad and passive margin, more than $150 \mathrm{~km}$ long, with maximum depths ranging between 100 and $140 \mathrm{~m}$ and a gentle slope on the order of 0.06 . The shoreface is extensive and shallow with an outer boundary at a depth of $10 \mathrm{~m}$, with predominantly sandy deposits (Toldo et al., 2006).

A good regional geomorphological description is given by Fachin (1998): according to this author, the shorefaces for the northern and southern end of this region are totally different, changing at the south of the Lagoa dos Patos inlet. The area near the south of Lagoa dos Patos is described as more homogeneous, with a gradually decreasing slope to- ward the sea. The northern and southern ends of this area have two different standards for the presence and orientation of sand ridges. To the north, there is a high concentration of sand ridges with an orientation predominantly parallel to the shoreline, with depths of 18 and $22 \mathrm{~m}$ and with coastal distances from 8 to $10 \mathrm{~km}$. At the southern end, there are more complex morphologies, with sand ridges oblique to the coast, directed predominantly from SE to NE, with depths between 12 and $30 \mathrm{~m}$.

The water level is also affected by the South Atlantic circulation responsible for short-term sea level variations. At Rio Grande do Sul, the maximum values of storm surges were on the order of 1, 1.4 and $1.9 \mathrm{~m}$, found by, Calliari et al. (1998b), Saraiva et al. (2003) and Parise et al. (2009), respectively. As tidal range is small, the waves are responsible for most sediment transport and deposition along the coast. The average significant wave height at depths of around $17 \mathrm{~m}$ is found by Strauch (2009) to be $1.5 \mathrm{~m}$.

According to Speranski and Calliari (2001), the convergence of wave rays due to refraction by small-scale bed slopes focuses the wave with a period longer than $9 \mathrm{~s}$ at some coastal areas. This is one of the probable causes of the local erosion under wave storms in Rio Grande do Sul.

Hermenegildo Beach, at the southern end of Rio Grande do Sul, has been studied often - e.g., by Calliari et al. (1998a) and Esteves et al. (2002, 2003) - because of the severe erosion problem in this region. According to Dillenburg et al. (2004), this problem involves anthropic occupation too. Toldo et al. (2006) have analyzed the retreat and progradation zone identifying a high regional coastal erosion along the middle coast between the Lagoa dos Patos inlet until the Tramandaí region as a function of longshore transport. The estimated potential of sediment transport predicts a substantial variation of the energy flux into the surf zone, due to little changes to shoreline alignments and consequently to the transport potential along the coast. The net longshore sand transport to the northeast is responsible for the increasing of coastal erosion rates. On the other hand, the reduction of the sediment flux among the alignments produce a jam in the longshore transport and the progradation in these places.

The effects of waves have been shown to be the fundamental process for coastal management, since it is the main forcing term in the dynamics, composition and morphology of this coastline. Most of the incoming wave energy incidents on this coastal zone are associated with gravity waves and the most energetic events are associated with the extra-tropical cyclones. These cyclones are very turbulent and unstable meteorological phenomena, defined as low-pressure systems of synoptic scale that occur in the mid-latitudes. They have a great influence on the regional climate and constitute an important mechanism of atmospheric circulation for the thermal equilibrium between the regions of low and high latitudes.

According to Machado et al. (2010), the intense cyclonic weather systems in southern Brazil generate ocean storms, which can, on a temporal scale varying from a few hours to 

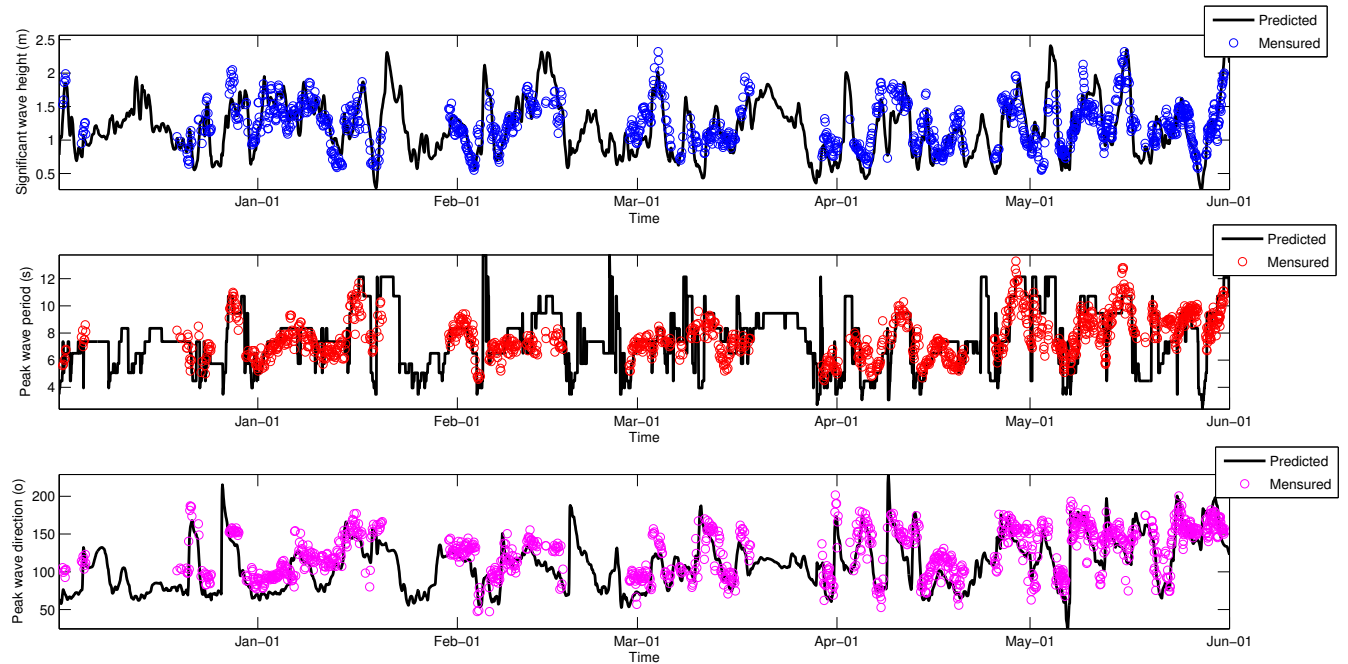

(a)
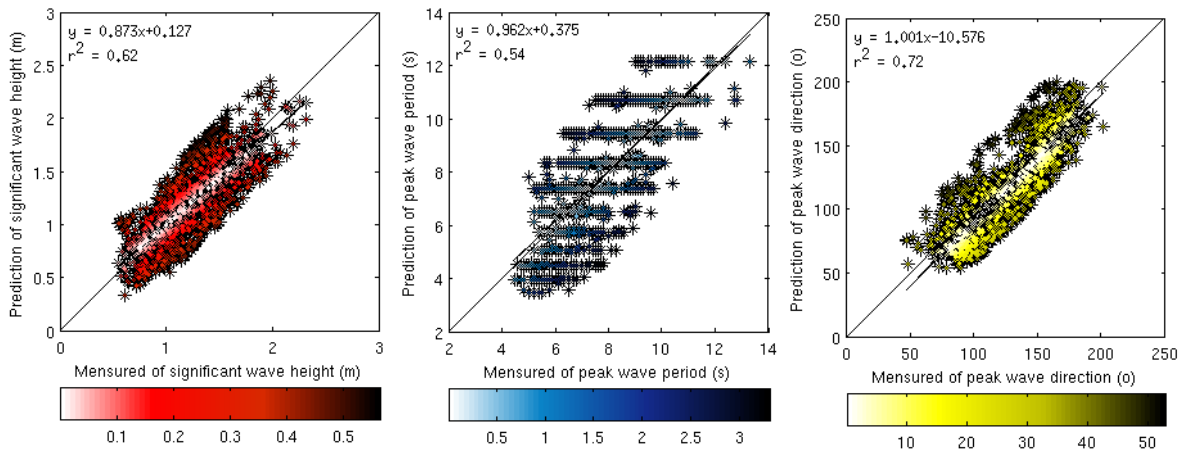

(b)

Figure 2. Validation of the SWAN wave model with the directional buoy data. (a) The SWAN predictions are shown in continuous lines and the buoy data are in circles. (b) Scatterplot of the linear correlation; the colors of the dots represent the distance from the regression line.

a day, completely erode a beach profile from its maximum accretion state. Mid-latitude cyclogenesis with low-pressure centers in the deep ocean and along the coast increases the intensity of Mid-Atlantic storms, causing storm surges and storm waves. During the event of September 2006, it was observed that a great part of Cassino Beach was flooded when the water reached the first avenue close to the beach.

Regarding the occurrence of extra-tropical cyclones in South America, Gan and Rao (1991), analyzing 10 years of data (from 1979 to 1988), have found that the majority of them happen in winter (eight events), followed by autumn (six events), spring (four events) and summer (three events). Gan and Rao (1991) identified two cyclogenesis regions in South America: one in Argentina (42.5 $\mathrm{S}$ and $62.5^{\circ} \mathrm{W}$ ), related to the baroclinic instability of the westerly winds, and another in Uruguay $\left(31.5^{\circ} \mathrm{S}\right.$ and $\left.55^{\circ} \mathrm{W}\right)$, associated with the baroclinic instability due to the presence of the Andes. Recently, a third region between 20 and $35^{\circ} \mathrm{S}$, located in southern and southeastern Brazil, was identified (Reboita et al., 2010).
Reboita et al. (2010), using the $10 \mathrm{~m}$ high wind field to calculate the relative vorticity $\left(\zeta_{10}\right)$, classified all the systems with $\zeta_{10} \leq-1.5 \times 10^{-5} \mathrm{~s}^{-1}$ as extra-tropical cyclones and a lifetime greater than or equal to $24 \mathrm{~h}$, and they found a total of 2787 cyclogenesis in 10 years over the South Atlantic Ocean. However, initially considering only the stronger systems with $\zeta_{10} \leq-2.5 \times 10^{-5} \mathrm{~s}^{-1}$, there is a well-characterized high frequency of cyclogenesis. Parise et al. (2009) and Machado et al. (2010) also classified three trajectory patterns over the southern Atlantic Ocean: the cyclogenesis in the south of Argentina with an eastward displacement and a trajectory between 47.5 and $57.5^{\circ} \mathrm{S}$ (RC1); the cyclogenesis in the south of Uruguay with an eastward displacement and a trajectory between 28 and $43^{\circ} \mathrm{S}$ (RC2); the cyclogenesis in the south of Uruguay with a southeasterly displacement and a trajectory between 35 and $57.5^{\circ} \mathrm{S}$ (RC3). Machado et al. (2010) include the high-pressure center generating an easterly wind as a fourth pattern of those events.

The extra-tropical cyclone of September 2006 was well studied by Parise et al. (2009), who shows that this particular storm caused a surge of $1.827 \mathrm{~m}$ at Cassino Beach. Although 
the surge was very high, these authors describe only a low level of beach erosion. This event was equally well classified and discussed by Machado et al. (2010), who included the regional cyclogenesis pattern RC3.

So, regarding the potential problem of storm waves, the geological history and the Mid-Atlantic cyclones, the aim of the present paper is to describe the development of high waves during extreme events at the coast of Rio Grande do Sul, and also to point to some places that could be at potential risk during these events.

\section{Materials and methods}

To accomplish this, we analyzed the cases of extreme waves that occurred between 2000 and 2010. To conduct this study, we analyzed the global wave data from WW3 (WAVEWATCH III) (Tolman, 2009), and the nearshore waves were simulated numerically with the spectral wave model SWAN (simulating waves nearshore) nested in WW3. Intending to validate this methodology, a computational simulation was run from December 2006 through May 2007. The model was started from rest condition in December, and run for 6 months, storing the results hourly. The results were compared with the directional buoy measurements from a buoy installed from November 2006 to May 2007, close to Tramandaí city (its location is indicated in Fig. 1), in $17 \mathrm{~m}$ intermediate waters (Strauch et al., 2009). Waves above $5 \mathrm{~m}$ of significant wave height by an offshore WW3 point were selected as the most extreme wave events. The simulation of each of these events was computed from the steady condition for 7 days before and 5 days after the peak of the event.

\subsection{Model description}

SWAN is a nearshore spectral wave model, efficient when predicting wave conditions for small scales, and for obtaining realistic estimates of wave parameters in coastal areas, lakes and estuaries, for prescribed wind, bottom and current conditions (Holthuijsen et al., 1993; Booij et al., 1999; Ris et al., 1999).

SWAN is based on the spectral action balance equation. Short-crested, random wave fields propagating simultaneously from widely varying directions can be simulated. The SWAN model accounts for shoaling, refraction due to spatial variations in bottom and current, diffraction, blocking and reflections, wave generation due to wind, energy dissipation due to white-capping, bottom friction, depth-induced breaking and nonlinear wave-wave interactions in both deep and shallow water (quadruplets and triads). The SWAN version used in these simulations is 40.72. A thorough description of the SWAN package and its background is in Young (1999) and Booij et al. (1999). In addition, the wave-induced setup of the mean sea surface was computed in SWAN.
We ran SWAN in nonstationary mode over a curvilinear grid, employing a 5 min time step, updating wind input every $3 \mathrm{~h}$, and the tides were forced hourly.

The computational grids are better resolved close to the coast area. The areas of low resolution are around $1.5 \mathrm{~km}$ in deep water and those of high resolution are $0.5 \mathrm{~km}$ in the coastal areas, rotated by $45^{\circ}$. The final grid contains 275200 cells, corresponding to an area around $250000 \mathrm{~km}^{2}$, covering all of the coastal zone of Rio Grande do Sul, and part of Uruguay and the state of Santa Catarina.

Every simulation was run over the same grid, considering the ETOPO $1^{1}$ bathymetry corrected with nautical charts provided by the DHN/CHM ${ }^{2}$ Brazil Marine through the Oceanographic Modeling and Observation Network (REMO).

\subsection{Boundary conditions and forcing}

The wave boundary conditions and the wind surface used are from the third generation wind wave model WAVEWATCH III (Tolman, 2009), operated by the wave modeling group at the National Center for Environmental Prediction (the wave hindcast database extends from 1999 to 2010 - see http://polar.ncep.noaa.gov/waves). They cover the globe in the domain $78-78^{\circ} \mathrm{N}$ with a grid resolution of $1^{\circ}$ in latitude and $1.25^{\circ}$ in longitude. This model outputs the wind speed and direction, as well as the integrated spectral parameters, such as the significant wave height $\left(H_{\mathrm{s}}\right)$, the peak period $\left(T_{\mathrm{p}}\right)$ and the mean direction at the peak period $\left(D_{\mathrm{p}}\right)$. The temporal data resolution is every $3 \mathrm{~h}$.

The data from WAVEWATCH III were nested in SWAN as boundary conditions every $3 \mathrm{~h}$. The intensity of the wind components $(U$ and $V$ ) were fit in a computational grid using linear interpolation based on a Delaunay triangulation of the data, and then the wind components were smoothed over the SWAN grid surface. The spectral wave boundary conditions from WAVEWATCH III were defined with a nonstationary distribution of Jonswap spectrum obtained by the waves' parameters $H_{\mathrm{s}}, T_{\mathrm{p}}$, and $D_{\mathrm{p}}$ and the directional spreading. This wave information came from the global results of WAVEWATCH III and was linearly interpolated to 60 equidistant points along the segments of the computational grid boundaries.

\subsection{Water level correlation}

The sea level exchange can be understood as a combination of the astronomical tide with the influence of the atmospheric level. To better represent the waves in shallow water during the analyzed events, the water levels were corrected by

\footnotetext{
${ }^{1}$ ETOPO1 is a 1 arcmin global relief model of the Earth's surface that integrates land topography and ocean bathymetry. For more information, see http://www.ngdc.noaa.gov/mgg/global/

${ }^{2}$ http://www.mar.mil.br/dhn/chm/box-cartas-nauticas/cartas. html
} 
directly employing the data measured by a tide gauge inside of the Tramandaí inlet from the Brazilian Superintendency of Ports and Waterways $\left(29.977^{\circ} \mathrm{S}, 50.124^{\circ} \mathrm{W}\right)$. The water levels were interpolated and included in the model each computational hour.

\subsection{Cyclone trajectories}

To analyze the cyclone trajectories that generated these waves, each cyclone's track and intensity were identified employing its relative vorticity $\left(\zeta_{10}\right)$ at the cyclone center given by

$\zeta_{10}=\left(\frac{\partial v_{10}}{\partial x}-\frac{\partial u_{10}}{\partial y}\right) \hat{k}$,

where $u_{10}$ and $v_{10}$ are the zonal and meridional wind components from WW3 at a $10 \mathrm{~m}$ height. $\hat{k}$ is the normal vector to the surface.

\section{Results}

\subsection{Model validation}

As mentioned before, wave data measured on the South Atlantic is extremely rare. For this study, we have carried out a simulation to compare the model's results with one of the few available observational data. Thus, the simulations were compared with measurements made by a directional buoy moored from November 2006 to May 2007 close to Tramandaí city (the location of which is indicated in Fig. 1) in $17 \mathrm{~m}$ of intermediate water (Strauch et al., 2009). This means that the buoy that is located over intermediate water depth could be measuring waves disturbed by the local bathymetry and is therefore not representative of the large-scale wave field. This analysis enabled the selection of the significant wave hight, the peak period and the peak direction (Fig. 2 shows these two dates at the same period).

Table 1 summarizes the statistical correlation between SWAN and the directional buoy data for the same data presented in Fig. 2.

$r$ represents the Pearson correlation coefficient, measuring the degree of correlation, and $a$ and $b$ are the regression line coefficients $(y=a x+b)$. The Pearson correlation is +1 in the case of a perfect positive (increasing) linear relationship (correlation), and 0 when there is low linear correlation between the variables (closer to uncorrelated or independent). According to Triola (2006), for a normal Pearson distribution, where $n=1175$ is the number of samples, the critical value for $|r|$ to exceed the significance levels of 99 and $95 \%$ (i.e., that the data has a chance of 1 or $5 \%$ of not being correlated) is 0.2560 and 0.1960 , respectively. For this case, a linear model, the coefficient of determination $r^{2}$ is Pearson's product-moment coefficient.

Looking at Figs. 2a and b, it is possible to see that the wave direction errors were near $10^{\circ}$ and the $r^{2}$ shows that the
SWAN could fit a coefficient of determination of 0.72 . But SWAN could not represent more than $53 \%$ of the variance for the peak wave periods; usually, the peaks of the swell period were underestimated and the sea peak waves' periods were overestimated. The significant wave heights were well represented by the model, with $r^{2}=0.62$. Usually the buoy registers were overestimated, however, in some of the higher events, the model underestimates on the order of $50 \mathrm{~cm}$ compared to that observed.

Overall, the model calibration results were reasonable and satisfactory at intermediate water waves. The coefficients of correlation between the model and the observed data were $0.79-0.85$. The error statistics showed that all three wave parameters analyzed had a good match with reality in most of the SWAN cases. The model slightly underestimated the significant wave heights. However, it follows the variation pattern of wave oscillation very soon, although small disagreements between the observed and the simulated data do exist.

\subsection{Extreme wave events}

The selected six events with waves higher than $5 \mathrm{~m}$ between 2000 and 2010 from WW3 point to coordinates $31^{\circ} \mathrm{S}$ and $50^{\circ} \mathrm{W}$. Table 2 shows some information about these events. The start time represents the time point at which the extreme significant wave height started to appear within the region of the computational grid. The end time point represents the points at which these wave events leave the computational grid. The peak time represents the most energetic time point of each simulation. The difference between the start and the end time point gives the duration of the event. Table 3 shows the maximum of significant wave height simulated $\left(H_{\mathrm{S}_{\max }}\right)$ observed in deep water, $W_{l_{\max }}$ represents the highest water level measured at the Tramandaí tide gauge during each event and $T_{\text {prreq }}$ and $D_{\text {preq }}$ give the period of the most frequent peak waves and the direction of the peak waves for each event in the whole computational domain.

The analysis of Tables 2 and 3 shows that the event of 27 June 2006 might be one of most energetic that has occurred in the Rio Grande do Sul coastal zone for the last 10 years; this time, the waves surpassed $9 \mathrm{~m}$ in height at offshore places. Figure 3 shows a simulation of the most energetic time point of this event. On a color scale, Figure 3a exhibits the significant wave heights over the computational grid, with the scale vector representing the peak wave direction. During this event, the formation of long wave periods was also observed, as was shown in Table 3; Fig. 3b exemplifies one screen of the peak wave period at this event.

\section{Discussion}

To closely analyze the selected cases, from the wind's vorticity analysis, it was possible to identify the patterns of synoptic situations for these event. Figure 4 presents the track 
Table 1. Model and buoy data statistics.

\begin{tabular}{lccc}
\hline & $H_{\mathrm{s}}$ & $T_{\mathrm{p}}$ & $D_{\mathrm{p}}$ \\
\hline Adjust equation & $y=0.87 x+0.13$ & $y=0.96 x+0.38$ & $y=1.00 x-10.58$ \\
$b$ & 0.1271 & 0.3751 & -10.5758 \\
$a$ & 0.8734 & 0.9618 & 1.0009 \\
$r^{2}$ & 0.6178 & 0.5388 & 0.7242 \\
$r$ & 0.7860 & 0.7340 & 0.8510 \\
\hline
\end{tabular}

Table 2. Extreme wave events: the start time gives the time at which the waves of these events started to appear in the computational domain. The end time indicates when the waves leave the domain. The peak time gives the most energetic moment in each event, and the duration is the time between the start and the end.

\begin{tabular}{lrrrr}
\hline Events & Start & End & Peak & Duration \\
\hline E01 & 30 Aug 2002, 15:00 & 4 Sep 2002, 00:00 & 2 Sep 2002, 15:00 & 4 days, 09:00 h \\
E02 & 26 Jun 2006, 12:00 & 28 Jun 2006, 18:00 & 27 Jun 2006, 03:00 & 2 days, 06:00 h \\
E03 & 2 Sep 2006, 19:00 & 6 Sep 2006, 11:00 & 3 Sep 2006, 19:00 & 3 days, 16:00 h \\
E04 & 27 Jul 2007, 09:00 & 30 Jul 2007, 06:00 & 28 Jul 2007, 13:00 & 2 days, 21:00 h \\
E05 & 3 May 2008, 04:00 & 6 May 2008, 11:00 & 3 May 2008, 23:00 & 3 days, 07:00 h \\
E06 & 9 Jun 2008, 22:00 & 11 Jun 2008, 02:00 & 10 Jun 2008, 10:00 & 1 days, 04:00 h \\
\hline
\end{tabular}

Table 3. Waves information for each events: $H_{\mathrm{S}_{\max }}$ is the max of significant wave height simulated at deep water, the $W_{1_{\max }}$ is the higher water level at a Tramandaí coastal point and the $T_{\mathrm{p}_{\text {freq }}}$ and the $D_{\text {freq }}$ are the most frequently of the peak wave period and the peak wave direction in the computational domain.

\begin{tabular}{lcccc}
\hline Events & $H_{\mathrm{S}_{\max }}[\mathrm{m}]$ & $W_{\mathrm{l}_{\max }}[\mathrm{m}]$ & $T_{\mathrm{p}_{\text {freq }}}[\mathrm{s}]$ & $D_{\mathrm{p}_{\text {freq }}}$ \\
\hline E01 & 7.254 & 0.83 & $12-14$ & $\mathrm{SE}$ \\
E02 & 8.982 & 0.84 & $12-14$ & $\mathrm{E}-\mathrm{SE}$ \\
E03 & 8.423 & 1.38 & $12-14$ & $\mathrm{E}$ \\
E04 & 8.351 & 0.90 & $12-14$ & $\mathrm{E}$ \\
E05 & 7.991 & 0.76 & $10-12$ & $\mathrm{~S}-\mathrm{SE}$ \\
E06 & 7.875 & 0.71 & $8-10$ & $\mathrm{NE}$ \\
\hline
\end{tabular}

of each event and the relative vorticity on a color scale. Employing the authors' classifications and the observations in Fig. 4, the majority of the events E01, E02, E04, E05 and E06 could be classified in pattern as regional RC2 with cyclogenesis in the south of Uruguay with an eastward displacement and a trajectory between 28 and $42.5^{\circ} \mathrm{S}$. Only the event E03 occurred at region RC3 with cyclogenesis in the south of Uruguay with a southeasterly displacement and a trajectory between 35 and $57.5^{\circ} \mathrm{S}$.

While only waves over $5 \mathrm{~m}$ were analyzed, the high frequency of events with pattern $\mathrm{RC} 2$ suggests that the eastward displacement of Mid-Atlantic cyclones best develops the extreme wave events on the Rio Grande do Sul coast. The extra-tropical cyclone of event E03 was well studied by Parise et al. (2009) and Machado et al. (2010): in this case, the meteorological scenario, due to a long wind fetch from $\mathrm{S}$ to SW and the association between this wind pattern and the
NE-SW orientation of the shoreline, favored the extra high rise in sea level observed on the coast due to the Coriolis effect. The events E04, E05 and E06 were the stronger systems, characterized by a high frequency of cyclogenesis with $\zeta_{10} \leq-2.5 \times 10^{-5} \mathrm{~s}^{-1}$.

To better understand how the waves developed during these events, Fig. 5 presents a Hovmöller diagram for significant wave heights. The diagram plots the wave data on a color scale, and the peak wave directions are displayed by vectors. This diagram shows the time as the abscissa ( $x$ axis) and the latitude of $50 \mathrm{~m}$ isobathymetry as the ordinate ( $y$ axis).

From Fig. 5, it is possible to observe that, during these events, the majority of wave energy at $50 \mathrm{~m}$ was concentrated between the latitudes 31.5 and $34^{\circ} \mathrm{S}$. Excluding the event E05, that concentrates the energy to the north of the Rio Grande do Sul littoral. The explication of this phenomenon is in the cyclogenic pattern. While most of the cyclones had displacements closer to the south coast, the E05 was the event that had the northernmost cyclogenic track. These observations allow us to say that the energy of the deep waves in the Rio Grande do Sul coastal zone during storm events are mostly concentrated in the southern portion of the state, controlled by the cyclone pattern $\mathrm{RC} 2$, with an eastward displacement between 28 and $43^{\circ} \mathrm{S}$. But an event like E05 can cause big waves at the northern region too, showing that the wave energy is fully related to the intensity and direction of the cyclone's track. Considering the recent cyclogenetic studies of Parise et al. (2009), Machado et al. (2010) and Reboita et al. (2012) provide us with information to determine that the south of the Rio Grande do Sul region collects most of the waves' energy at $50 \mathrm{~m}$ deep water during extreme events. 


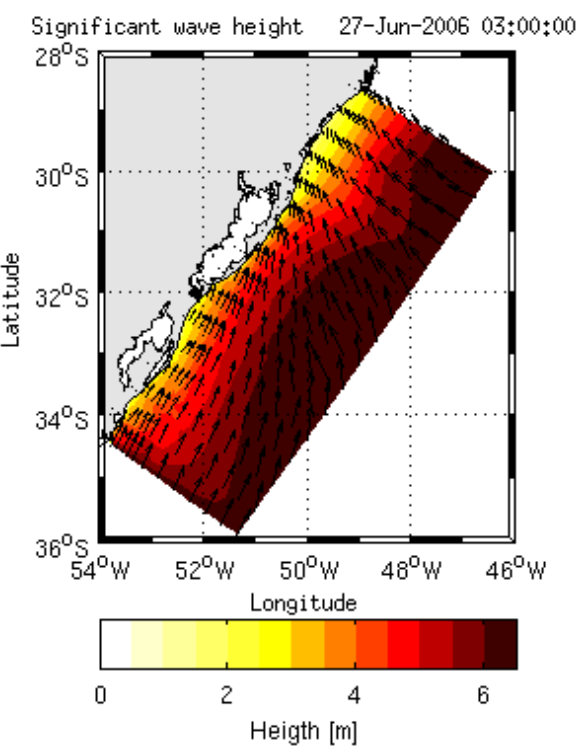

a) $H s$ and $D p$ of EVENT 02

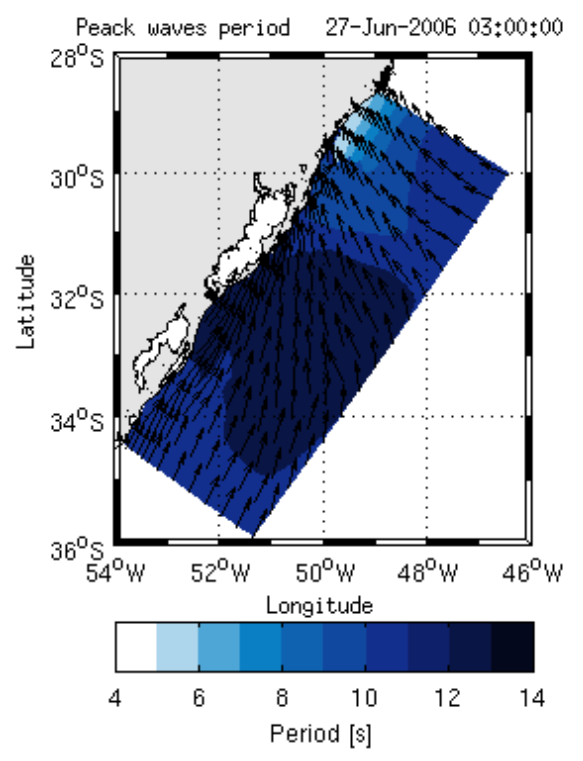

(b) $T p$ and $D p$ of EVENT 02

Figure 3. Wave field maps for the event 02. (a) Significant wave height $\left(H_{\mathrm{s}}\right)$ in meters and (b) peak wave period $\left(T_{\mathrm{p}}\right)$. The peak wave directions $\left(D_{\mathrm{p}}\right)$ are presented in scale vectors.

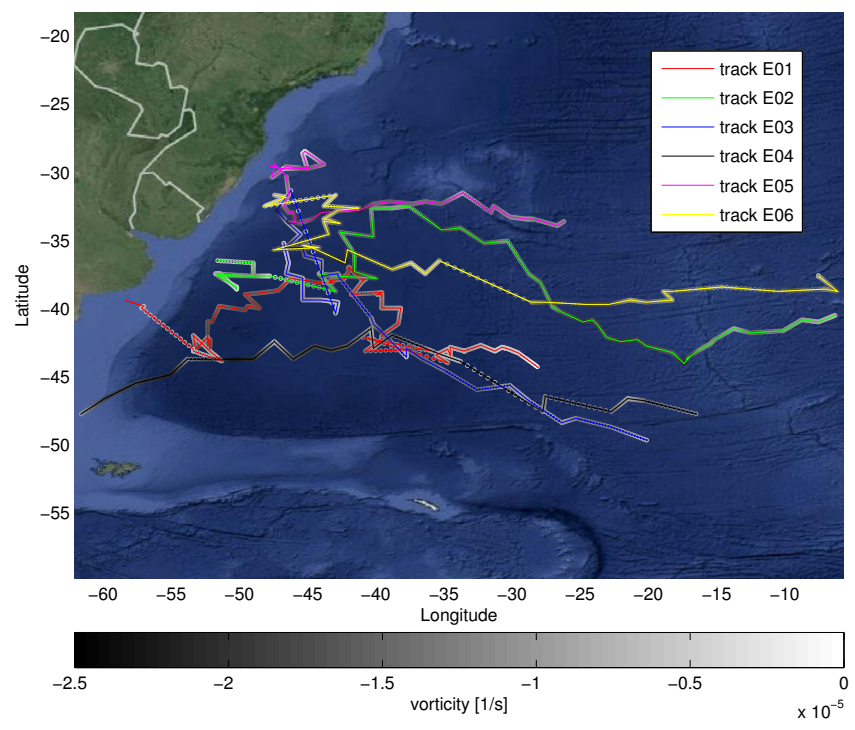

Figure 4. From the colored lines, it is possible to identify each anticyclone track per event, and the gray balls show the vorticity intensity.

The wave analysis of the $50 \mathrm{~m}$ deep water waves provides important information for evaluating the risk for navigation and offshore operations, but is insufficient for coastal zone studies. So, Fig. 6 presents the same Hovmöller analysis for the waves at $6 \mathrm{~m}$ depth.

Unlike the $50 \mathrm{~m}$ wave analysis, Fig. 6 shows that the waves' energy during these extreme events was concentrated to the north of Rio Grande city and at the Hermenegildo
Beach region. The explanation of this fact is not just in the cyclone's pattern, but also in the shoreface morphologies. The region next to the lagoon's mouth (south) has a completely different shoreface morphology compared to that at the northern and the southern end of Rio Grande do Sul.

The region south of the mouth of the Lagoa dos Patos presents a wide inner shelf, virtually homogeneous, with isobaths parallel to the coastline until next to Hermenegildo Beach (seen also in Fig. 1). In this region, close to Hermenegildo Beach $\left(33.2^{\circ} \mathrm{S}\right)$, the subaqueous profile has remnants of sand ridges.

The region north of the Lagoa dos Patos inlet $\left(32.2^{\circ} \mathrm{S}\right)$ is characterized by a large concentration of sand ridges oriented at shoreline oblique, predominantly in NE-SE directions, and between the 12 and $30 \mathrm{~m}$ isobaths. Also, along with a narrowing of the region of the shoreface, where the largest profile slopes occur, with is predominantly sandy sedimentology. So, these bottom features corroborate the results obtained by the analysis of the waves in shallow water. Due to the gentle and smooth slope in the region south of the Lagoa dos Patos, most of the wave energy is dissipated at the shoreface. The natural features in this region act like a natural submerged barrier to the wave impact during these extreme events. In contrast, the high bathymetric gradients and the different submerged features observed north of the Lagoa dos Patos outflow showed a tendency to concentrate the energy of the shallow water waves during the analyzed events. In such cases, the phenomena of refraction and friction with the background become more significant, due to the large peak wave periods (seldom found in typical wave fields), more often between 12 and $14 \mathrm{~s}$ 

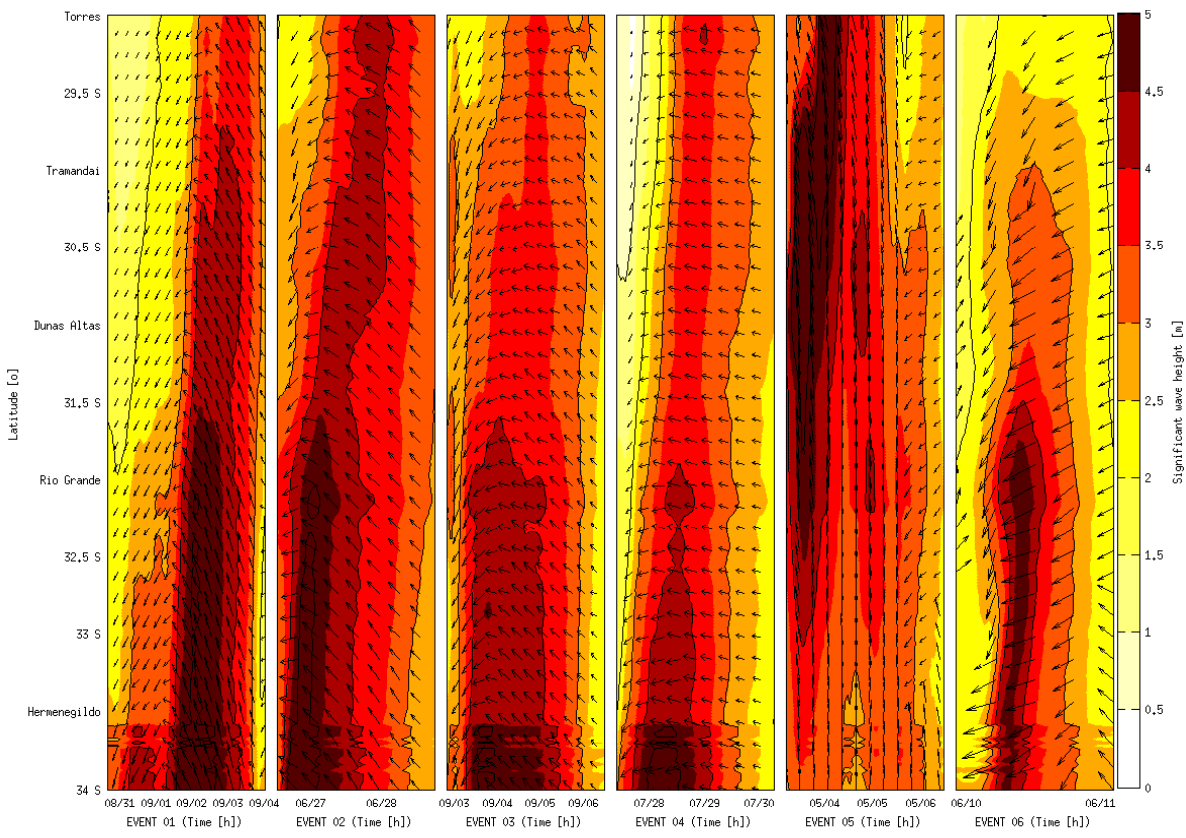

Figure 5. Hovmöller diagram for deep water waves. The diagram displays the wave parameters $\left(H_{\mathrm{S}}\right.$ and $\left.D_{\mathrm{p}}\right)$ for $50 \mathrm{~m}$ isobathymetry. The latitude of the wave is displayed along the $y$ axis, and the time is shown along the $x$ axis. The $H_{\mathrm{s}}$ are on a color scale and the $D_{\mathrm{p}}$ are shown as vectors.
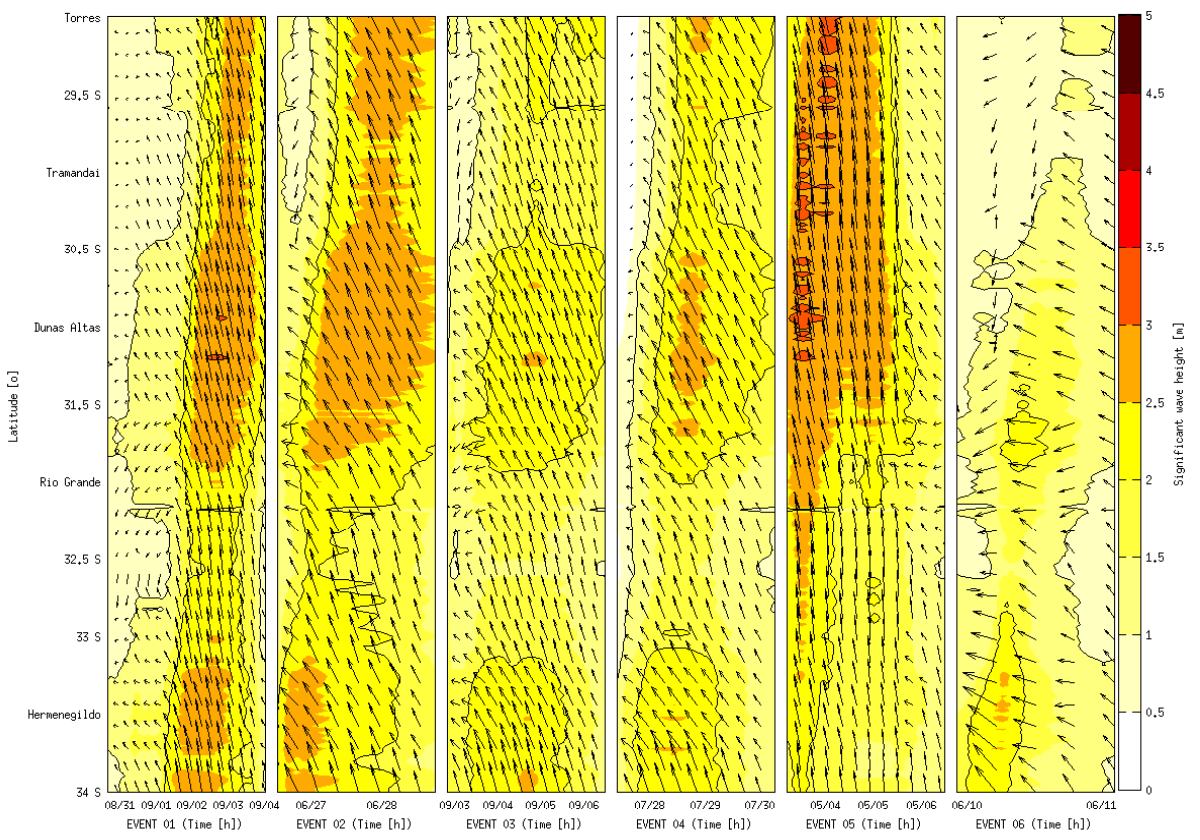

Figure 6. Hovmöller diagram for shallow water waves. The diagram displays the wave parameters $H_{\mathrm{s}}$ and $D_{\mathrm{p}}$ for $6 \mathrm{~m}$ isobathymetry. The latitude of the wave is displayed along the $y$ axis, and the time is shown along the $x$ axis. The $H_{\mathrm{s}}$ are on a color scale and the $D_{\mathrm{p}}$ are shown as vectors.

To better understand the interaction between the Rio Grande do Sul shallow water waves and the morphologies, Fig. 1 shows the nearshore bathymetry between 0 and $-60 \mathrm{~m}$. These results support the results of the Hovmöller diagram for shallow water waves (Fig. 6), wherein the wave energy has been concentrated by the high slope gradients.

Although the erosion problem in the further south of Rio Grande do Sul at Hermenegildo has mainly been a problem of anthropic occupation, this wave analysis shows that 
this problem can also be associated with the cyclogenesis pattern and the wave transformation at the shoreface, where the waves' energy has been concentrated in front of Hermenegildo.

However, the trends of the shoreline are established by the extreme erosive and depositional results of the complex interaction between the rates of relative changes in the sea level, the rate of sediment supply, the wave dynamics and the impacts produced by storm waves. However, because of the large energy carried by the waves of 2 to $3 \mathrm{~m}$ in shallow water, combined with the sea leave rise of 0.7 to $1.3 \mathrm{~m}$ during extreme events, the sedimentary dynamics during these high wave energy events are an important factor in the sediment budget of the sand beaches.

The results of Toldo et al. (2006) about a high coastal retreat from the north of the Lagoa dos Patos inlet to the Tramandaí region are also related to Fig. 6, where one can observe a trend in the waves' energy at this part of the littoral. Toldo et al. (2013) also classified the sectors in front of Mostardas $\left(31^{\circ} \mathrm{S}\right)$ and Dunas Altas $\left(30.5^{\circ} \mathrm{S}\right)$ as sediment sink areas. The region of lower wave energy between the Rio Grande and about $33^{\circ} \mathrm{S}$ was classified by Toldo et al. (2006) as an area of progradation and moderate retrogradation. Except for the event E05, which had a different cyclonic trajectory from the others, the analysis of Fig. 6 also allows the observation of a small region of lower wave energy just north of Tramandaí beach; at this area, the progradation and moderate retrogradation rates were also checked by Toldo et al. (2006). Therefore, these authors' results conform to the shallow water wave analysis presented in this article, thus showing that the high-energy wave events could be one of the causes of somo beaches erosion along the coast of Rio Grande do Sul.

However, other factors, such as currents, beach profile, sea level, grain size, etc., have been extremely important for the sediment dynamics of the region. The morphological response and amplitude caused by a storm are often defined as proportional to the intensity of waves and the tidal level of high energy (as described by Wright and Short, 1984; Wright et al., 1985; Sénéchal et al., 2009). So, the results of this study are directly in agreement with those found by Toldo et al. (2006) and Toldo et al. (2013) after storm events, thus suggesting that the dynamics induced by extreme wave events can be one of the determinants of sediment transport in the region, being one of the major contributors to the large volumes of sedimentary mobilization, moving the sediment from areas of largest wave height toward offshore areas or towards areas of lower wave energy. In addition, the waves that hit the coast during these events were mainly affected by the regional shoreface morphology and by the cyclone pattern that generated these events.

While most of Rio Grande do Sul is highly prone to coastal erosion, much of the coast is still preserved with low urbanization. Crossing the results of significant wave height with the urbanization and use, it is possible to determine that Hermenegildo Beach $\left(33.2^{\circ} \mathrm{S}\right)$, Cidreira $\left(30.2^{\circ} \mathrm{S}\right)$, Pinhal $\left(30.3^{\circ} \mathrm{S}\right)$, Tramandaí and Imbé $\left(30.0^{\circ} \mathrm{S}\right)$ and Torres $\left(29.3^{\circ} \mathrm{S}\right)$ should pay more attention to the passage of extreme wave events. The analysis of deep water waves suggests that more attention should be given to the region next to Rio Grande $\left(32.1^{\circ} \mathrm{S}\right)$, where one of the most important ports of Brazil is located, and the risks are directly related to navigation and offshore operations.

\section{Summary and conclusions}

Employing some of the studies and measured wave data for the Rio Grande do Sul, this paper reviewed the extreme wave events there from 2000 to 2010 . Spectral wave modeling with a good spatial resolution (around $1 \mathrm{~km}$ ) and nonstationary high-frequency time resolution $(5 \mathrm{~min}$ ) allowed a good numerical representation of the waves. The high grid resolution that was employed in the areas of interest allowed a good simulation of the waves, where the buoy data were available for validating this simulation. Overall, the comparison of the measured buoy data with the model results showed that there was a reasonable fit, and have been satisfactory for shallow water waves. The statistical results showed that all three wave parameters analyzed had a good match with reality in most of the SWAN cases, with correlation coefficients between 0.79 and 0.85 . It has to be emphasized that comparison studies of this type are extremely rare and scarce in the South Atlantic. Thus, the results here are new and relevant to future works on the modeling and description of the wave fields in this domain of the globe's oceans.

The direct analysis of deep water waves from WW3 identified six events between 2000 and 2010, where the waves surpassed $5 \mathrm{~m}$ of significant height on a point of interest. Employing the Mid-Atlantic cyclonic pattern classification, it was possible to detect a high frequency of events of pattern RC2 among all events with high wave energy. This suggests that the eastward displacement of Mid-Atlantic cyclones develop the extreme wave events on the Rio Grande do Sul coast more intensively.

The pattern RC2 did better at developing highly energetic events between the latitudes 31.5 and $34^{\circ} \mathrm{S}$, but the simple formation of these events at the north, as for event E05, could change the deep water wave pattern. This shows that the highly energetic wave patterns in deep water are mostly controlled by the cyclonic track and intensity.

The Hovmöller diagram for shallow and deep water analysis allows a good description of the time evolution for each event. The wave analysis in $50 \mathrm{~m}$ deep water could provide important information for navigation and offshore operations risk, while the shallow water analysis, at $6 \mathrm{~m}$ deep, shows where most of the waves' energy was dissipated or concentrated along the Rio Grande do Sul shoreface.

These results agree with the Rio Grande do Sul geomorphological description. The wave energy tends to be concentrated in areas of higher gradients of bathymetry and with 
heterogeneous bottom morphology, in front of Hermenegildo Beach and to the north of the Lagoa dos Patos inlet. But, to the south of the Lagoa dos Patos inlet, the gentle and smooth slope dissipates most of the wave energy at the shoreface, acting as a natural submerged barrier to the waves' impact during these extreme events. The wave pattern found during these events in deep water showed a greater concentration of wave energy south of $31.5^{\circ} \mathrm{S}$, while, in shallow waters, this pattern was inverted, with focus of the wave energy mainly to the north of $31^{\circ} \mathrm{S}$.

The wave pattern in shallow water during these events is also in accordance with the coastal progradation and retraction areas of this coast, showing that the concentration and the dissipation of the waves' energy at shoreface during extreme events could be one of the main factors responsible for the sediment budget on the Rio Grande do Sul coast.

Finally, another key aspect of this storm wave analysis involves the assessment of the risk conditions for each examined beach. As a consequence, this paper could determine the sensitive places during storm wave occurrences for urban occupation, navigation and offshore activities.

Acknowledgements. The first author would like to thank CAPES (Coordenação de Aperfeiçoamento de Pessoal de Nível Superior) for a research fellowship and financial support from CNPq. Pedro V. Guimarães and Leandro Farina have done part of the research on this article at the Basque Center for Applied Mathematics (BCAM), while members of the EU project number FP7-295217-HPC-GA. The authors also would like to thank Brazil's Superintendency of Ports and Waterways for making the water level data available.

Edited by: I. Didenkulova

Reviewed by: two anonymous referees

\section{References}

Almeida, L. P., Vousdoukas, M. V., Ferreira, Ó., Rodrigues, B. A., and Matias, A.: Thresholds for storm impacts on an exposed sandy coastal area in southern Portugal, Geomorphology, 143144, 3-12, doi:10.1016/j.geomorph.2011.04.047, 2012.

Booij, N., Ris, R. C., and Holthuijsen, L. H.: A thirdgeneration wave model for coastal regions: 1. Model description and validation, J. Geophys. Res., 104, 7649-7666, doi:10.1029/98JC02622, 1999.

Calliari, L. J., Speranski, N., and Boukareva, I.: Stable focus of waves rays as a reason of local erosion at southern Brazil coast, J. Coastal Res., 26, 19-23, 1998a.

Calliari, L. J., Tozzi, H. A. M., and Klein, A. H. F.: Beach morphology and coastline erosion associated with storm surges, An. Acad. Bras. Ciênc., 70, 232-247, 1998 b.

Dillenburg, S. R., Esteves, L. S., and Tomazelli, L. J.: A critical evaluation of coastal erosion in Rio Grande do Sul, Southern Brazil, Ann. Brazil. Acad. Sci., 76, 611-623, 2004.

Esteves, L. S., Toldo, E. E., Dillenburg, S. R., and Tomazelli, L. J.: Long- and short-term coastal erosion in Southern Brazil, J. Coastal Res., 282, 273-282, 2002.
Esteves, L. S., da Silva, A. R. P., Arejano, T. B., Pivel, M. A. G., and Vranjac, M. P.: Coastal development and human impacts along the Rio Grande do Sul Beaches, Brazil, J. Coastal Res., 35, 548556, 2003.

Fachin, S.: Caracterização do Perfil de Equilíbrio da Antepraia na Costa do Rio Grande do Sul, PhD thesis, Universidade Federal do Rio Grande do Sul, 1998.

Gan, M. A. and Rao, B. V.: Surface ciclogenesis over South America, Mon. Weather Rev., 119, 293-302, 1991.

Holthuijsen, L. H., Booij N., and Ris R. C.: A spectral wave model for the coastal zone, Proceedings 2nd International Symposium on Ocean Wave Measurement and Analysis, New Orleans, Louisiana, 25-28 July, New York, 630-641., 1993.

Machado, A. A., Calliari, L. J., Melo, E., and Klein, A. H. F.: Historical assessment of extreme coastal sea state conditions in southern Brazil and their relation to erosion episodes, Pan-American J. Aquatic Sci., 5, 105-114, 2010.

Mendoza, E. and Jimenez, J.: Storm-induced beach erosion potential on the Catalonian Coast, J. Coastal Res., SI 48, 81-88, 2006.

Mendoza, E. and Jimenez, J.: Regional geomorphic vulnerability analysis to storms for Catalan beaches, P. I. Civil Eng.-Mar. En., 162, 127-135, 2009.

Morton, R.: Factors controlling storm impacts on coastal barriers and beaches: a preliminary basis for near real-time forecasting, J. Coastal Res., 18, 486-51, 2002.

Parise, C. K., Calliari, L. J., and Krusche, N.: Extreme storm surges in the south of brazil: atmospheric conditions and shore erosion, Braz. J. Oceanogr., 57, 175-188, 2009.

Reboita, M. S., Rocha, R. P., and Ambrizzi, T.: Dynamic and climatological features of cyclonic developments over Southwestern South Atlantic Ocean, in: Horizons in Earth Science Research, Vol. 6, chap. 4, Nova Science Publishers, São Paulo, 135-160, 2012.

Reboita, M. S. O., da Rocha, R. P., Ambrizzi, T., and Sugahara, S.: South Atlantic Ocean cyclogenesis climatology simulated by regional climate model (RegCM3), Clim. Dynam., 35, 1331-1347, 2010.

Ris, R. C., Holthuijsen, L. H., and Booij, N.: A third-generation wave model for coastal regions: 2. Verification, J. Geophys. Res., 104, 7667, doi:10.1029/1998JC900123, 1999.

Sallenger, A.: Storm impact scale for barrier islands, J. Coastal Res., 16, 890-895, 2000.

Saraiva, J. M. B., Bedran, C., and Carneiro, C.: Monitoring of storm surges at Cassino Beach, J. Coastal Res., SI 35, 323-331, 2003.

Sénéchal, N., Gouriou, T., Castelle, B., Parisot, J., Capo, S., and Bujan, S., H. H.: Morphodynamic response of a meso- to macrotidal intermediate beach based on a long-term data set, Geomorphology, 107, 263-274, 2009.

Speranski, N. and Calliari, L.: Bathymetric lenses and localized coastal erosion in Southern Brazil, J. Coastal Res., 34, 209-215, 2001.

Strauch, J. a. C., Cuchiara, D. C., Júnior, E. E. T., and de Almeida, L. E. S. B.: O Padrão das Ondas de Verão e Outono no Litoral Sul e Norte do Rio Grande do Sul, RBRH - Revista Brasileira de Recursos Hídricos, 14, 29-37, 2009.

Toldo, E., Nicolodi, J., Almeida, L., Corrêa, I., and Esteves, L.: Coastal dunes and shoreface width as a function of longshore transport, J. Coastal Res., 39, 390-394, 2006. 
Toldo, E. E., da Motta, L. M., de Almeida, L. E. d. S. B., and Nunes, J. C. R.: Large morphological change linked to the sediment budget in the Rio Grande do Sul Coast, Coast. Dynam., 7th International Conference on Coastal Dynamics, 1687-1696, 2013.

Tolman, H. L.: User manual and system documentation of WAVEWATCH-III, Tech. rep., NOAA/NWS/NCEP/OMB, 2009.

Triola, M.: Elementary Statistics, 10 Edn., Pearson Education, Boston, 2006
Wright, L. and Short, A.: Morphodynamic variability of surf zones and beaches: a synthesis, Mar. Geol., 56, 93-118, 1984.

Wright, L., Short, A., and Green, M.: Short-term changes in the morphodynamic states of beaches and surf zones: an empirical predictive model, Mar. Geol., 62, 339-364, 1985.

Young, I.: Wind Generated Ocean Waves, 1st Edn., Elsevier, University of Adelaide, Australia, 1999. 